Research paper

\title{
Decomposition of methane hydrate for hydrogen production using microwave and radio frequency in-liquid plasma methods
}

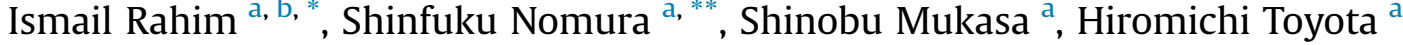 \\ ${ }^{a}$ Graduate School of Science and Engineering, Ehime University, Matsuyama 790-8577, Japan \\ b Department of Automotive Engineering Education, State University of Makassar, Makassar 90222, Indonesia
}

\section{H I G H L I G H T S}

- The decomposition of methane hydrate is proposed using plasma inliquid method.

- Synthetic methane hydrate is used as the sample for decomposition in plasma.

- Hydrogen can be produced from decomposition of methane hydrate.

- Hydrogen purity is higher when using radio frequency stimulation.

\section{A R T I C L E I N F O}

\section{Article history:}

Received 30 October 2014

Accepted 26 June 2015

Available online 9 July 2015

\section{Keywords:}

Methane hydrate

In-liquid plasma

Radio frequency

Microwave oven

Decomposition

Hydrogen production
G R A P H I C A L A B S T R A C T

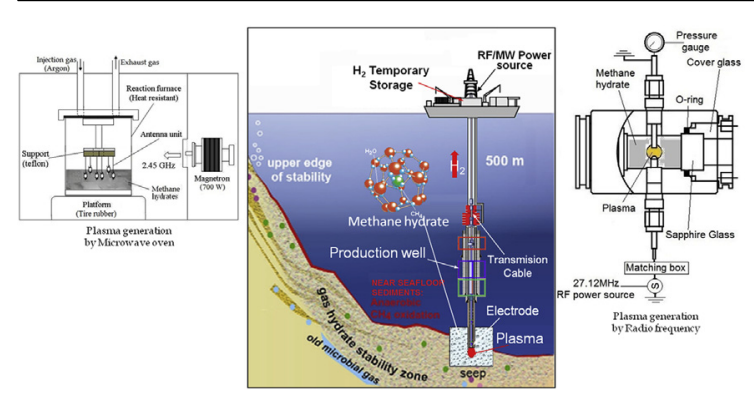

\begin{abstract}
A B S T R A C T
This research involves two in-liquid plasma methods of methane hydrate decomposition, one using radio frequency wave (RF) irradiation and the other microwave radiation (MW). The ultimate goal of this research is to develop a practical process for decomposition of methane hydrate directly at the subsea site for fuel gas production. The mechanism for methane hydrate decomposition begins with the dissociation process of methane hydrate formed by $\mathrm{CH}_{4}$ and water. The process continues with the simultaneously occurring steam methane reforming process and methane cracking reaction, during which the methane hydrate is decomposed releasing $\mathrm{CH}_{4}$ into $\mathrm{H}_{2}, \mathrm{CO}$ and other by-products. It was found that methane hydrate can be decomposed with a faster rate of $\mathrm{CH}_{4}$ release using microwave irradiation over that using radio frequency irradiation. However, the radio frequency plasma method produces hydrogen with a purity of $63.1 \%$ and a $\mathrm{CH}$ conversion ratio of $99.1 \%$, which is higher than using microwave plasma method which produces hydrogen with a purity of $42.1 \%$ and $\mathrm{CH}_{4}$ conversion ratio of $85.5 \%$.
\end{abstract}

() 2015 Elsevier Ltd. All rights reserved.

\section{Introduction}

Hydrogen seems to be one of the more promising energy sources since it is both environmentally friendly and highly

* Corresponding author. Graduate School of Science and Engineering, Ehime University, Matsuyama 790-8577, Japan. Tel.: +81 89927 9723; fax: +81 89927 9744.

** Corresponding author.

E-mail addresses: ismail_rahim@unm.ac.id (I. Rahim), nomura.shinfuku.mg@ ehime-u.ac.jp (S. Nomura). energy efficient. The total of energy yield of hydrogen combustion is greater than that of any other fuel [1,2]. Consequently, intense research has been conducted on hydrogen production as an energy source with a variety of methods being proposed such as water electrolysis [3], steam reforming for fossil fuels [3,4], ethanol and methanol reforming [2,5], clathrate hydrate reforming [6], multi-generation energy production system [4,7], conversion of hydrocarbons by microwave plasma or conventional microwave oven [8-10], radio frequency plasma stimulation [11], just to name a few. 
Furthermore, Methane hydrate is increasingly becoming one of the more promising energy resources due to its abundance [12], and potential role in mitigating global climate change $[13,14]$. It is formed by its constituent $\mathrm{CH}_{4}$ molecules held within the lattice cavities of water crystals occurring via an exothermic reaction under the proper combination of pressure and temperature [15]. Methane hydrate is an untapped source of hydrocarbon energy [16], which is believed to be both plentiful and stable on the seabed and in permafrost at high pressure and low temperature $[10,12,17]$. The amount of energy held in methane hydrate beneath the sea could possibly be as much or even more than twice that of the entire energy reserves of the various fossil fuels on Earth [12]. Its considerable C: $\mathrm{H}$ ratio and availability make it an attractive energy source for producing hydrogen and could be preferable to the currently most commonly used mode of hydrogen production, steam methane reforming (SMR), which in commercial application supplies from 80 to $85 \%$ of the world's hydrogen [14].

Interest in methane hydrate has increased over the last several years, with many governments including those of the USA, Canada, Russia, India, and Japan becoming intrigued by the possibilities of methane hydrate $[12,13]$. In the process of investigating methane hydrate as an alternative potential source of hydrogen energy, a significant number of methods for extracting hydrogen through methane hydrate decomposition have been recommended and developed. Methane hydrate has a pressure phase equilibrium of $2.3 \mathrm{MPa}$ at $0{ }^{\circ} \mathrm{C}$ and consists of an ice/liquid water hydrate $[12,16]$. It has been exploited for natural gas production through the dissociation process. One hydrate dissociation process involves heating hydrate fields through thermal stimulation to a temperature above the hydrate equilibrium temperature. The thermal stimulation method typically employs injecting hot water (steam and hot brine) into the hydrate field. Unfortunately, the production cost of this method is quite high due to the high energy loss during injection of the hot water [16]. On the other hand, the use of high-frequency waves irradiated directly into the hydrate field can prove to be a more rapid and effective method than the hot-water injection [10].

Moreover, the radio frequency wave and microwave in-liquid plasma method use a technology in which plasma is generated inside bubbles within a liquid creating a high-temperature chemical reaction field $[2,18-20]$. The temperatures of the in-liquid plasma exceed $3000 \mathrm{~K}$ at atmospheric pressure [18]. In-liquid plasma has been employed in the decomposition of waste oils or hydrocarbon liquids during which the useful by-products, hydrogen gas and carbon particles are generated simultaneously [9]. MW plasma, which can be generated using commercial microwave ovens, is commonly used in diamond depositions and IC manufacturing and has the advantages of simple and low-priced operation, high plasma density and high electron mean energy $[2,21]$. When $2.45 \mathrm{GHz}$ of microwave plasma is generated in a hydrocarbon liquid, hydrogen gas with a purity of $66 \%-80 \%$ can be produced, which means that the energy efficiency of hydrogen production with this method is estimated to be $56 \%$ over that by electrolysis of alkaline water for the same power consumption $[9,22]$. On the other hand, radio frequency (RF) plasma irradiation could easily be used to generate plasma in water under high pressure [18] with the energy consumption required to produce hydrogen, oxygen, and hydrogen peroxide from water under atmospheric pressure being $0.4 \%$ of the $150 \mathrm{~W}$ of radio frequency input power [11]. This means that RF plasma could be generated at a lower power than microwave plasma in water. Therefore, it is feasible to use RF irradiation for methane hydrate decomposition from hydrate fields as a foreseeable method of hydrogen production by plasma stimulation.
In the present study, decomposition of methane hydrate at atmospheric pressure by radio frequency wave (RF) and microwave (MW) plasma is conducted to compare the attributes of these two methods. This becomes a first step in the process with the ultimate goal of producing hydrogen from hydrate fields using an in-liquid plasma method as shown in Fig. 1.

The in-liquid plasma method generates a high localized temperature at high pressure with the plasma remaining mostly around the tip of the electrode [6]. This makes the method proposed ideal for this purpose. During the initial process of plasma generation in methane hydrate, the hydrate would melt and pass from a solid phase into a liquid phase, hence, the plasma generated in methane hydrate can be considered as the in-liquid plasma.

\section{Experiment apparatus \& procedure}

\subsection{Methane hydrate formation}

The apparatus for formation of methane hydrate is shown in Fig. 2. The apparatus consists of a cooling bath, temperature control device, magnetic stirrer, methane gas supply, thermocouple and pressure measurement unit. Methane hydrate was formed by injecting pressurized methane gas into shaved ice in the cooling bath.

The inner diameter and height of the cooling bath are $60 \mathrm{~mm}$ and $140 \mathrm{~mm}$, respectively, giving it a volume of $400 \mathrm{ml}$. The maximum pressure is $15 \mathrm{MPa}$, and temperature of the cooling bath is maintained using ethylene glycol as a cooling medium. A magnetic stirrer with a diameter of $40 \mathrm{~mm}$ along with a methane injection tube is positioned $30 \mathrm{~mm}$ from the bottom of the cooling bath. $100 \mathrm{~g}$ of shaved ice were put into the cooling bath which has been washed by water. The temperature of cooling bath was maintained constant at $0{ }^{\circ} \mathrm{C}$, the methane was pressurized to about $7 \mathrm{MPa}$ and the magnetic stirrer rotated at $500 \mathrm{rpm}$ to agitate the solution of methane gas and shaved ice. The temperature of methane hydrate formation was recorded by a thermocouple located $30 \mathrm{~mm}$ from the bottom of the cooling bath, while pressure change was recorded by a camera connected to a computer unit. Pressure and temperature throughout the procedure were recorded every $15 \mathrm{~min}$.

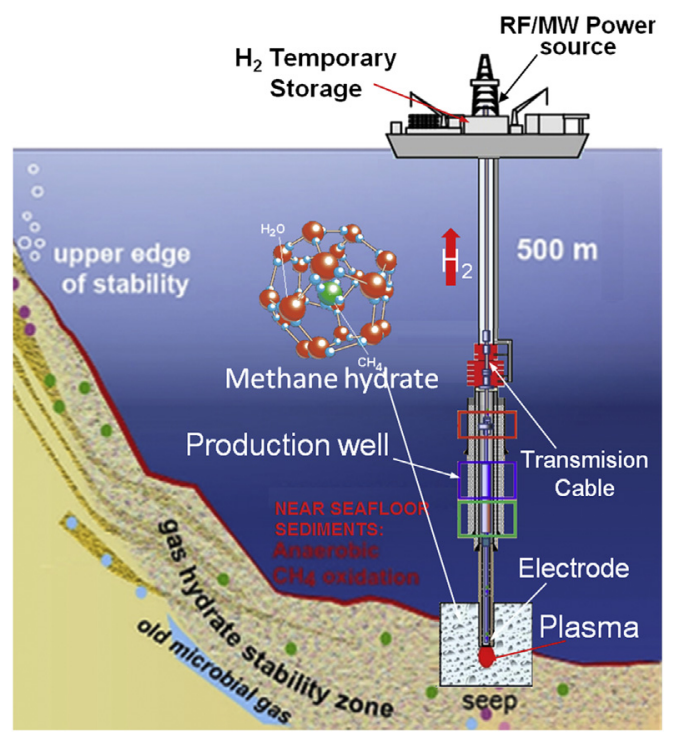

Fig. 1. Process for hydrogen production from hydrate fields in subsea sites using the inliquid plasma method. 


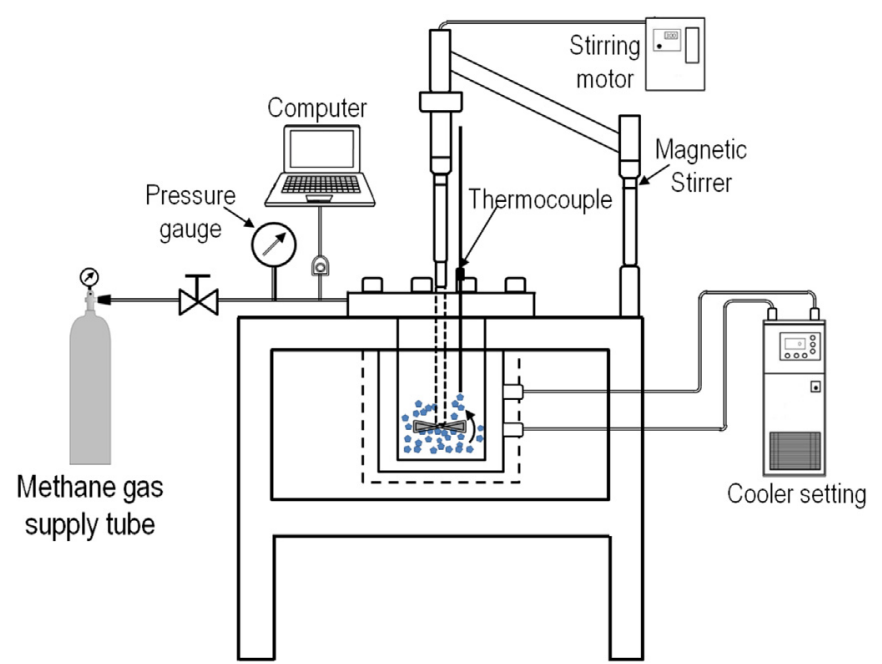

Fig. 2. Apparatus for synthesizing methane hydrate.

During the formation of methane hydrate, there was an initial increase in temperature to approximately $6{ }^{\circ} \mathrm{C}$. The process then continued constantly as the ice melted. The remainder of the ice melted to create hydrates when the cooling bath temperature fell to $2{ }^{\circ} \mathrm{C}$ [6]. Pressurization at $7 \mathrm{MPa}$ was maintained by repeatedly injecting methane [15]. The pressure remained constant at $7 \mathrm{MPa}$ until the end of the procedure. It then rapidly decreased to atmospheric pressure while additional refrigeration was conducted. The further cooling is necessary to prevent hydrate dissociation [23].

\subsection{Plasma decomposition from methane hydrate using radio frequency wave}

The experimental apparatus for RF plasma decomposition is shown in Fig. 3. Radio frequency plasma with a frequency of 27.12 MHz was used to decompose methane hydrate. Argon gas was injected into the reactor vessel to expel air before plasma generation at the electrode tip and methane hydrate was decomposed in the reactor vessel at atmospheric pressure.

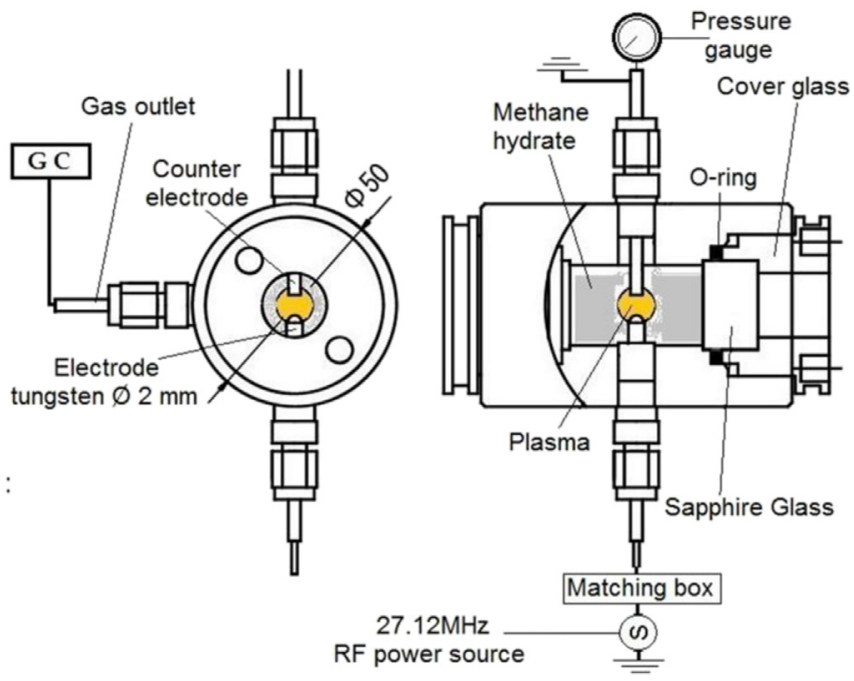

Fig. 3. Experimental apparatus using RF plasma decomposition.
An electrode made of a $2 \mathrm{~mm}$ tungsten rod protruding from a ceramic tube used as a dielectric substance $10 \mathrm{~mm}$ in length with an outer diameter of $6 \mathrm{~mm}$ and $1.5 \mathrm{~mm}$ thickness was inserted into the reactor through the bottom and connected to a power source (T161-5766LQ Thamway) via a matching box (T0205766M).

Additionally, a copper tube was inserted from the top of the reactor to a distance of $4 \mathrm{~mm}$ from the lower electrode that functioned both as a counter electrode and a gas exhaust outlet. $10 \mathrm{~g}$ of methane hydrate were put into the reactor vessel. The RF input power was set to range from 300 to $350 \mathrm{~W}$ at atmospheric pressure. The net power values were calculated by subtraction of the reflected power from the forward power. The reflected power was maintained constant at the lowest value possible.

\subsection{Plasma decomposition from methane hydrate using microwave oven}

A conventional microwave oven was utilized as the microwave power source for generating the plasma with the antennas positioned facing downwards as shown in Fig. $4.10 \mathrm{~g}$ of methane hydrate were inserted under the tips of the antennas inside the reactor vessel. . The reactor vessel was irradiated by microwaves from a $700 \mathrm{~W}$ magnetron with the antennas receiving $2.45 \mathrm{GHz}$ of microwaves at which point plasma was generated at the tip of each antenna.

In order to prevent the microwave energy from being absorbed by components inside the reactor such as the reaction vessel, the reactor platform and piping were made using heat-resistant glass and silicone rubber. In addition, the antenna unit was installed on a Teflon ${ }^{\circledR}$ base so that the reactor vessel would not be damaged by the heat generated by the plasma [6]. The electrode tips protrude into the methane hydrate and plasma starts generating the fluidphase. The gas produced was collected using a syringe after it was expelled by the downward displacement of water into a pipe inserted through the top of the device and connected to the reactor vessel. Argon gas (Ar) was piped into the reactor filled with methane hydrate to extract the exhaust gases. In this condition, MW irradiation was applied and plasma generated resulting in approximately $1000 \mathrm{ml}$ of generated gas being recovered using the water substitution method.

A Shimadzu 8A gas chromatograph with a column temperature $60{ }^{\circ} \mathrm{C}-160{ }^{\circ} \mathrm{C}$ (hold $6 \mathrm{~min}$ ) utilizing Argon as the carrier gas was

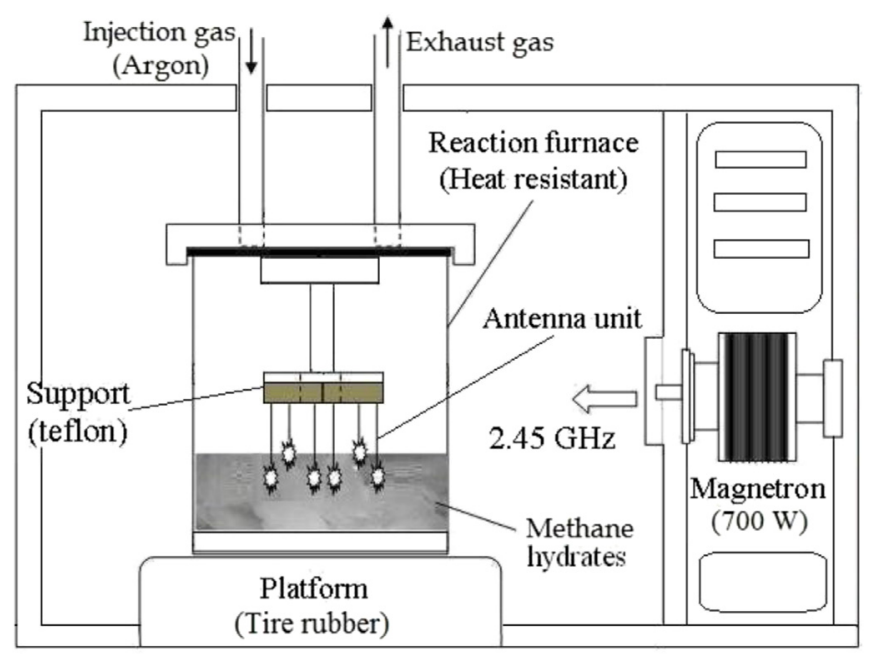

Fig. 4. Experimental apparatus for plasma generation using microwave oven. 


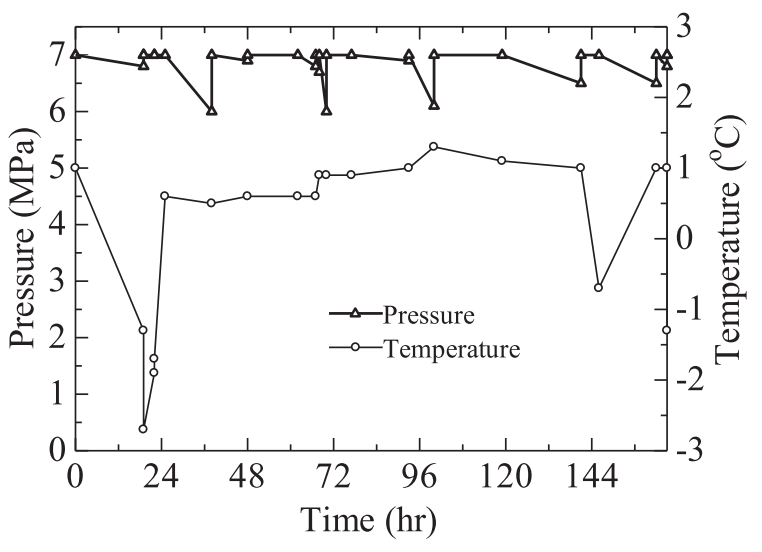

Fig. 5. Pressure \& temperature during methane hydrate formation.

used to identify the contents of the exhaust gases from both the RF and the MW plasma methods.

\section{Results and discussion}

Methane hydrate has a cubic structure I (sI) with a unit cell formula of $6\left(5^{12} 6^{2}\right) 0 \cdot 2\left(5^{12}\right) \cdot 46 \mathrm{H}_{2} \mathrm{O}[12,14,15,17]$. The basic formula for methane hydrate is $\mathrm{CH}_{4} \cdot n \mathrm{H}_{2} \mathrm{O}$, where $n$ is the stoichiometric number or hydrate number which describes a variable number of water molecules within the lattice structure of methane hydrate. Based on the pressure condition of 1.9-9.7 MPa and the formation temperature of 253-285 K, the sample of synthetic methane hydrate used in this experiment had a stoichiometric number of $n=5.81-6.10 \mathrm{H}_{2} \mathrm{O}$ with an average of $\mathrm{CH}_{4} .5 .99( \pm 0.07) \mathrm{H}_{2} \mathrm{O}$ [24]. Methane hydrate began forming rapidly in the cooling bath after the stirrer was activated, and there was a concurrent pressure decrease to about 6.7 MPa and temperature increase to around $1^{\circ} \mathrm{C}$. This was caused by an exothermic reaction, as shown in Fig. 5.

Methane hydrate was then decomposed by the plasma into the product gases which were hydrogen $\left(\mathrm{H}_{2}\right)$ and carbon monoxide (CO) as the main products, and carbon dioxide (CO), methane $\left(\mathrm{CH}_{4}\right)$, carbon $(\mathrm{C})$, and hydrocarbon $\left(\mathrm{C}_{\mathrm{x}} \mathrm{H}_{\mathrm{y}}\right)$ as byproducts [2], the same composition was also reported by Nomura et al. [3].

Some amounts of carbon black appeared due to the readily available methane molecules during the decomposition [1,9]. As a result, carbon was found adhered to the reactor walls, antennas and counter electrodes. Also, decomposition of methane hydrate at the copper interface of the antenna in the microwave oven resulted in dissolution of carbon into the metal and dispersion as particles. The carbon then precipitated at the copper base of the antenna. The condition of the antennas before and after methane hydrate decomposition using MW plasma is shown in Fig. 6.

The results of the plasma decomposition of methane hydrate showed that there remains asubstantial amount of methane in the product gases from unconverted methane release. As can be seen in Fig. 7, about $36 \%$ of the product gas was $\mathrm{CH}_{4}$ when the methane hydrate decomposition was conducted by the MW plasma method and $17.3 \%$ by the RF plasma method at an input power of $330 \mathrm{~W}$ in comparison to $20 \%$ from $n$-dodecane by the MW plasma method in previous experimentation by Nomura et al. [9].

Essentially, the electromagnetic wave from a microwave oven has three principal properties; its wave will be reflected by metal material such as steel or iron, it is able to penetrate a non-metallic material without heat transfer [1], and most significantly, it is easily absorbed by water. Electromagnetic waves from MW oven radiation can transfer enough energy to heat water by the excitation of its molecules which leads to the enhancement of the overall temperature inside, and finally results in water turning into steam [10].

Therefore, it was hypothesized that some portions of water and methane from the reaction of methane hydrate dissociation were vaporized and rose up out of the liquid without passing through the plasma decomposition process for producing hydrogen. This would explain the reason for a significant amount of unconverted methane release in the product gases for the MW oven method, which was more than twice that of the RF plasma method.

It took $60 \mathrm{~s}$ to collect $60 \mathrm{~mL}$ of the gas generated from methane hydrate decomposition by the RF plasma method. However, $1100 \mathrm{~mL}$ of generated gas was collected in $60 \mathrm{~s}$ by the MW plasma method. The result of gas chromatography analysis of the recovered gas is shown in Table 1 with the addition of the recovered gas results of $n$-dodecane from previous experiment for comparison.

The entirety of the reactions can be expressed by the following:

$$
\begin{aligned}
& \mathrm{CH}_{4} \cdot n \mathrm{H}_{2} \mathrm{O} \rightarrow x\left(a \mathrm{H}_{2}+b \mathrm{CO}+c \mathrm{CO}_{2}+d \mathrm{CH} 4+e \mathrm{C}_{2} \mathrm{H}_{2}+f \mathrm{C}_{2} \mathrm{H}_{4}\right)+ \\
& y \mathrm{C}(\mathrm{s})+z \mathrm{H}_{2} \mathrm{O}
\end{aligned}
$$

Where, $a, b, c, e, f$ are the contents ratio of product gases as shown in Table 1.

$$
\begin{aligned}
& x=2 /(a-b-2 c+2 d+e+2 f) \\
& y=(a-3 b-4 c-3 e-2 f) /(a-b-2 c+2 d+e+2 f)
\end{aligned}
$$

and
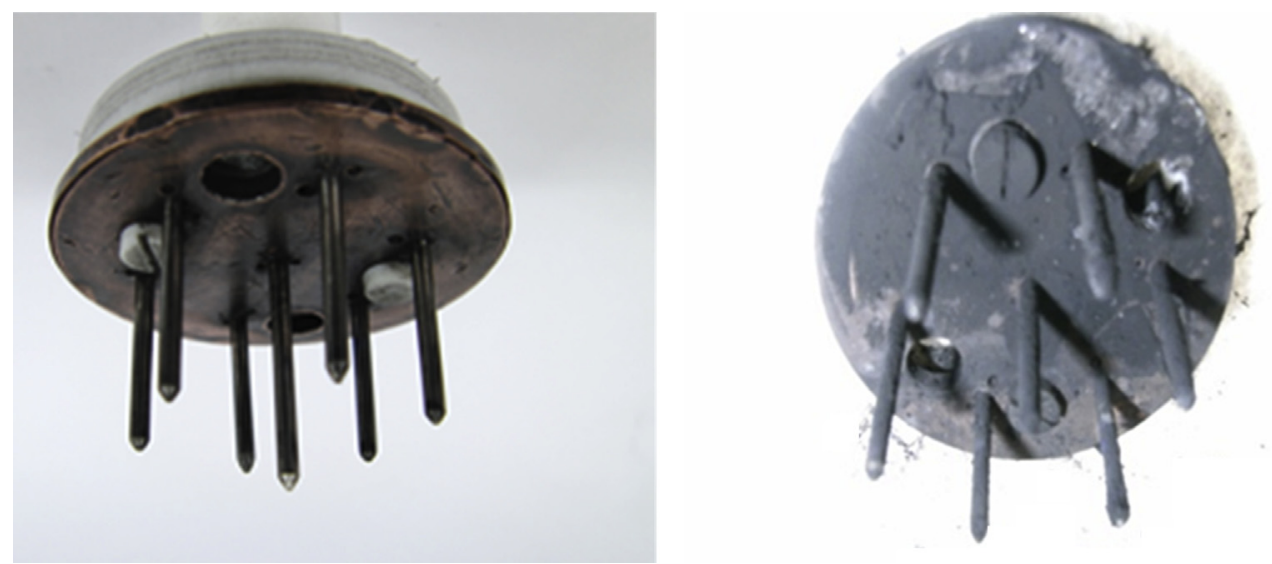

Fig. 6. Condition of antennas/electrodes before and after methane hydrate decomposition. 


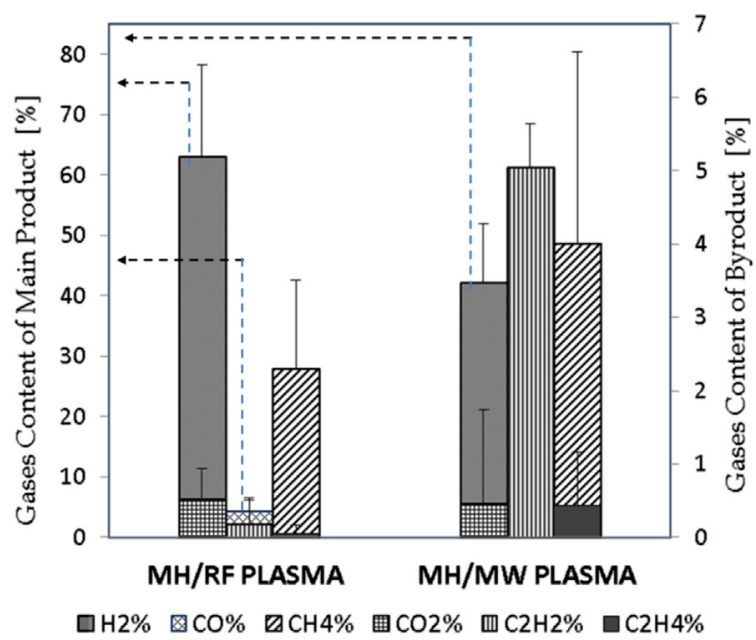

Fig. 7. Content of product gases from methane hydrate decomposition.

$z=n-2(b+2 c) /(a-b-2 c+2 d+e+2 f)$

The chemical reaction of plasma decomposition of methane hydrate shown in Eq. (1) is based on methane hydrate dissociation (MHD), steam methane reforming (SMR) and methane cracking reaction (MCR). At the beginning of the MHD reaction, $\mathrm{CH}_{4}$ and water were produced, then the SMR and the MCR reactions simultaneously decompose the released $\mathrm{CH}_{4}$ into $\mathrm{H}_{2}, \mathrm{CO}$ and other byproducts. The water that turns into steam by the plasma reacting with the $\mathrm{CH}_{4}$ to produce $\mathrm{H}_{2}, \mathrm{CO}$ and $\mathrm{CO}_{2}$ through the SMR process [11]. The reaction equation and enthalpies concerned with MHD, SMR and MCR are shown in Table 2.

The molarity of these mixed of product gases is expressed as $n_{\text {gas }}$ and becomes:

$$
\begin{aligned}
& \text { From } \mathrm{MH} / \mathrm{RF} \text { plasma decomposition } \rightarrow a=n_{\mathrm{H} 2} \\
& =0.642 \cdot n_{\text {gas }}
\end{aligned}
$$

$b=n_{\mathrm{CO}}=0.045 \cdot n_{\text {gas }}$

$c=n_{\mathrm{CO} 2}=0.005 \cdot n_{\text {gas }}$

$d=n_{\mathrm{CH} 4}=0.287 \cdot n_{\text {gas }}$

Table 1

The contents of the gas generated by the RF plasma and the MW plasma.

\begin{tabular}{lllllll}
\hline & $\mathrm{H}_{2} \%$ & $\mathrm{CO} \%$ & $\mathrm{CH}_{4} \%$ & $\mathrm{CO}_{2} \%$ & $\mathrm{C}_{2} \mathrm{H}_{2} \%$ & $\mathrm{C}_{2} \mathrm{H}_{4} \%$ \\
\hline MH/RF plasma & 64.2 & 4.5 & 28.8 & 0.5 & 0.2 & 0.1 \\
MH/MW plasma & 42.1 & 3.3 & 48.6 & 0.5 & 5.0 & 0.4 \\
n-Dodecane/MW plasma [9] & 74.0 & 0.0 & 2.0 & 0.0 & 20.0 & 2.0
\end{tabular}

Table 2

Basic reactions of methane hydrate decomposition.

\begin{tabular}{lll}
\hline Reactions & Category & $\Delta H(\mathrm{~kJ} / \mathrm{mol})$ \\
\hline $\mathrm{CH}_{4} \cdot 6 \mathrm{H}_{2} \mathrm{O} \rightarrow \mathrm{CH}_{4}+6 \mathrm{H}_{2} \mathrm{O}(\mathrm{l})$ & Methane hydrate dissociation & $53.5[25]$ \\
$\mathrm{CH}_{4}+\mathrm{H}_{2} \mathrm{O} \rightarrow 3 \mathrm{H}_{2}+\mathrm{CO}$ & Steam methane reforming & 206.16 \\
$\mathrm{CO}+\mathrm{H}_{2} \mathrm{O} \rightarrow \mathrm{H}_{2}+\mathrm{CO}_{2}$ & Steam methane reforming & -41.2 \\
$\mathrm{CH}_{4} \rightarrow 2 \mathrm{H}_{2}+\mathrm{C}(\mathrm{s})$ & Methane cracking reaction [1] & 74.87 \\
$2 \mathrm{CH}_{4} \rightarrow 3 \mathrm{H}_{2}+\mathrm{C}_{2} \mathrm{H}_{2}$ & Methane cracking reaction & 376.47 \\
$2 \mathrm{CH}_{4} \rightarrow 2 \mathrm{H}_{2}+\mathrm{C}_{2} \mathrm{H}_{4}$ & Methane cracking reaction & 202.21 \\
\hline
\end{tabular}

$e=n_{\mathrm{C} 2 \mathrm{H} 2}=0.002 \cdot n_{\text {gas }}$

$f=n_{\mathrm{C} 2 \mathrm{H} 4}=0.0006 \cdot n_{g a s}$

The enthalpy of formation per $1 \mathrm{~mol}$ of methane hydrate by the reaction can be determined when the chemical reaction formulas in Table 2 are substituted in Eq. (1). Accordingly,

$$
\begin{gathered}
x\left[a \Delta H\left(\mathrm{H}_{2}\right)+b \Delta H(\mathrm{CO})+c \Delta H\left(\mathrm{CO}_{2}\right)+d \Delta H\left(\mathrm{CH}_{4}\right)+e \Delta H\left(\mathrm{C}_{2} \mathrm{H}_{2}\right)\right. \\
\left.+f \Delta H\left(\mathrm{C}_{2} \mathrm{H}_{4}\right)\right]+z \Delta H\left(\mathrm{H}_{2} \mathrm{O}\right)-\Delta H(\mathrm{MH})=369 \mathrm{~kJ} / \mathrm{mol}
\end{gathered}
$$

was obtained. In the same manner as the enthalpy calculation, $368 \mathrm{~kJ} / \mathrm{mol}$ of enthalpy of formation was found for the MW plasma method. That there is a positive enthalpy of formation indicates an endothermic reaction for which energy input was required [1]. The enthalpy of formation per $1 \mathrm{~L}$ of gas in the reaction in Eq. (1) was $9.73 \mathrm{~kJ} / \mathrm{L}$ which was supplied by methane hydrate decomposition by the RF plasma method. In the same manner, up to $11.46 \mathrm{~kJ} / \mathrm{L}$ was obtained by the MW plasma method.

In this experiment, the power consumption of the RF plasma method was $327.5 \mathrm{~W}$ to decompose methane hydrate for an irradiation time of $60 \mathrm{~s}$ which produced $54 \mathrm{~mL}$ of gas. Whereas the MW plasma method consumed $700 \mathrm{~W}$ and took $48 \mathrm{~s}$ to produce $550 \mathrm{~mL}$ of gas. If the energy is converted into a unit per liter gas ratio, it was found to be $401.5 \mathrm{~kJ} / \mathrm{L}$ for the RF plasma method and $65.8 \mathrm{~kJ} / \mathrm{L}$ for the MW plasma method. As a result, the amount of energy required to generate $1 \mathrm{~mol}$ of $\mathrm{H}_{2}$ for each plasma methods was found to be $12.7 \mathrm{MJ} / \mathrm{mol}(=(327.5 \mathrm{~W}) \times(60 \mathrm{~s}) \times(22.4 \mathrm{~L} / \mathrm{mol}) /(0.054 \times 0.642 \mathrm{~L}))$ for the RF method and $4.1 \mathrm{MJ} / \mathrm{mol}(=(700 \mathrm{~W}) \times(60 \mathrm{~s}) \times(22.4 \mathrm{~L} /$ $\mathrm{mol}) /(0.55 \times 0.421 \mathrm{~L})$ for the MW method.

Additionally, further analysis showed that during methane hydrate decomposition by the MW plasma method, the formation of acetylene was a main factor for the energy expansion. The enthalpy of formation of acetylene is $376.47 \mathrm{~kJ} / \mathrm{mol}$ as shown in Table 2, which is greater than that of other substances. In addition, it can be seen from the data in Table 1 that the percentage of acetylene in the gas content was as much as $5.1 \%$ which is greater than that from methane hydrate decomposition using the RF plasma method. Thus, reaction conditions should be defined so as to inhibit the formation of acetylene in the process of hydrogen production [6].

The $\mathrm{CH}_{4}$ conversion rate was affected by the rate of methane hydrate dissociation, which should be equal to the gas production rate. The total $\mathrm{CH}_{4}$ conversion ratio was calculated using Equation (12) [11]:

$\mathrm{CH}_{4}$ conversion ratio $=\left[\frac{\left(\mathrm{CH}_{4}\right)_{\text {reactant }}-\left(\mathrm{CH}_{4}\right)_{\text {product }}}{\left(\mathrm{CH}_{4}\right)_{\text {reactant }}}\right] \times 100$

$\left(\mathrm{CH}_{4}\right)_{\text {reactant }}$ was determined by the number of moles of $\mathrm{CH}_{4}$ trapped in $10 \mathrm{~g}$ of methane hydrate, and $\left(\mathrm{CH}_{4}\right)_{\text {product }}$ was the number of moles of $\mathrm{CH}_{4}$ content in the product gases. Referring to the hydrate number $(n)=6.0$ [6], the amount of $\mathrm{CH}_{4}$ trapped in $10 \mathrm{~g}$ of methane hydrate is thought to be $0.0806 \mathrm{~mol}$.

The actual $\mathrm{CH}_{4}$ content in the product gases was $0.0115 \mathrm{~mol}$ for the MW plasma method and 0.00069 mol for the RF plasma method. Subsequently, it can be seen from Fig. 8 that the total $\mathrm{CH}_{4}$ conversion ratio tended to decrease with an increase of the $\mathrm{H}_{2}$ content in the product gases for both plasma decomposition methods, a comparable trend is also observed for the CO content in the product gases.

$\mathrm{H}_{2}$ selectivity was determined by the number of $\mathrm{H}$ atoms in the $\mathrm{H}_{2}$ content of the product gases, divided by the total of $\mathrm{H}$ atoms in 

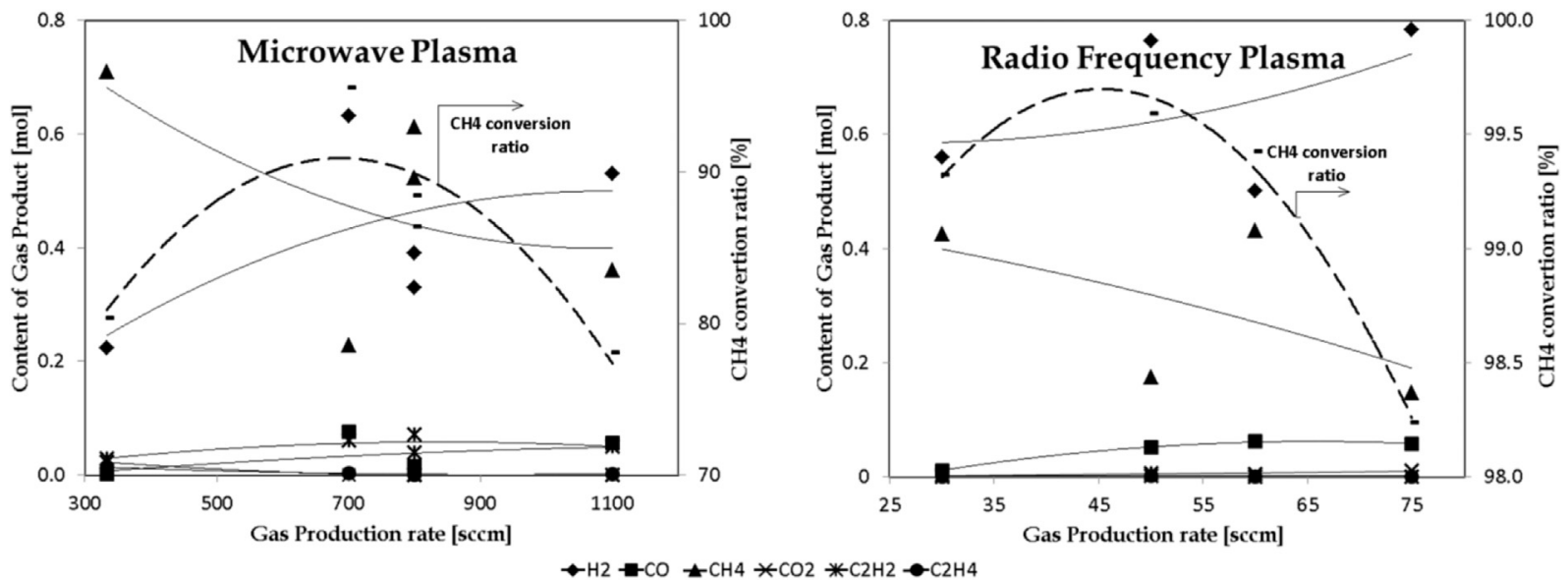

Fig. 8. $\mathrm{CH}_{4}$ conversion ratio for methane hydrate decomposition by the RF and the MW Plasma method.
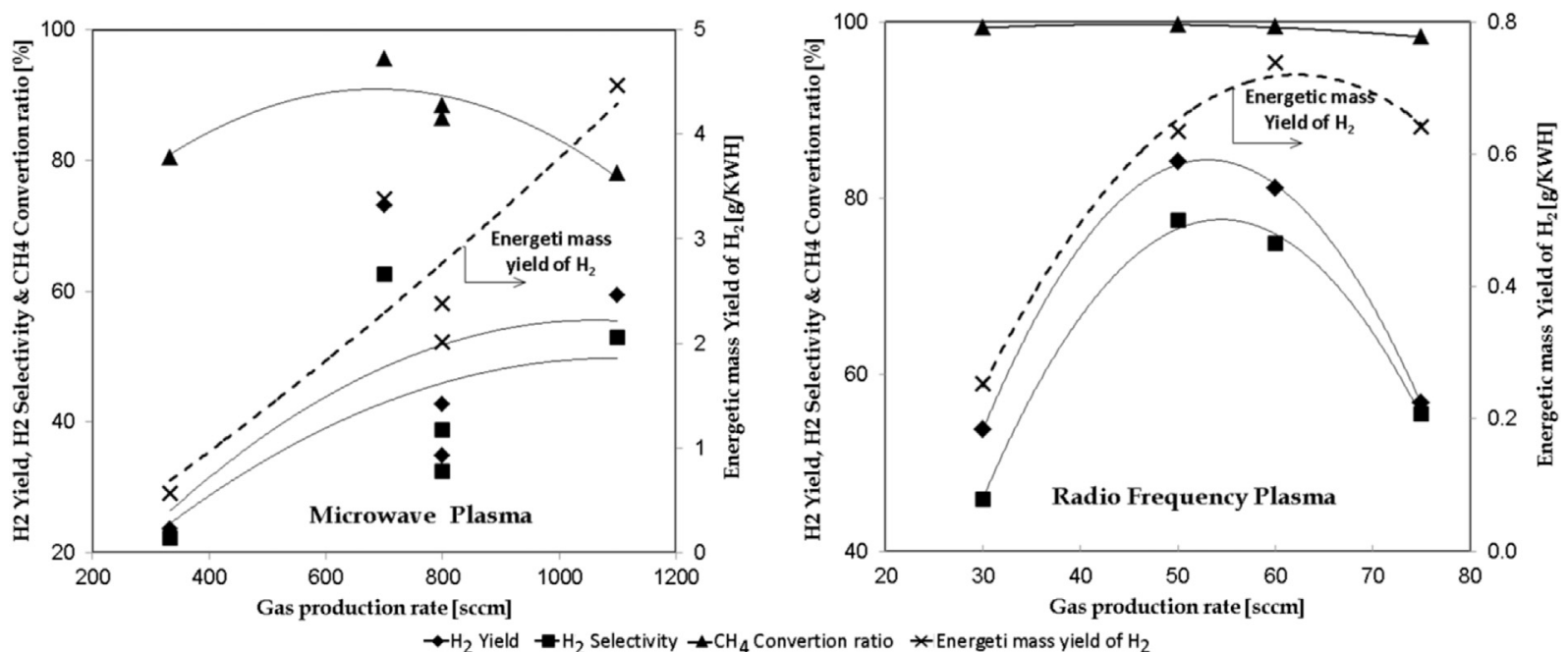

Fig. 9. $\mathrm{H}_{2}$ selectivity \& $\mathrm{H}_{2}$ yield by the MW and the RF Plasma method.

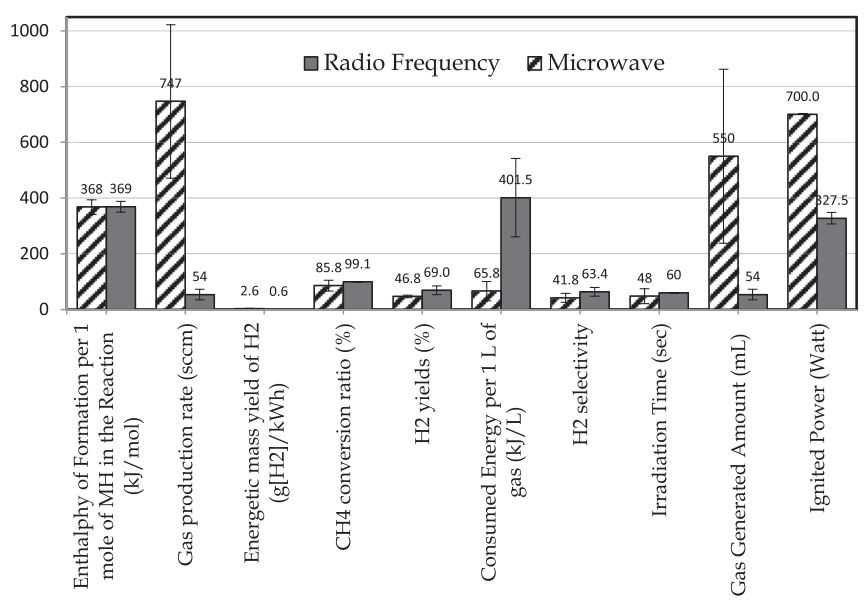

Fig. 10. Comparison summary of performance results of plasma decomposition by MW \& RF methods.

the converted reactant [11]. Likewise, $\mathrm{H}_{2}$ yield is the number of $\mathrm{H}$ atoms in the $\mathrm{H}_{2}$ content of the product gases, divided by the total of $\mathrm{H}$ atoms in the reactant. Fig. 9 shows that the selectivity and yield of $\mathrm{H}_{2}$ by the MW method tends to increase with a rise of the gas production rate. On the other hand, the selectivity and yield of $\mathrm{H}_{2}$ by the RF method tended to increase with a slow rate of gas production, while it tended to decrease at a faster rate.

The $\mathrm{H}_{2}$ energetic mass yield for the RF plasma method was up to $0.6 \mathrm{~g}\left[\mathrm{H}_{2}\right] / \mathrm{kWh}$ with a $\mathrm{CH}_{4}$ conversion ratio of $99.1 \%$ (Fig. 8), while for the MW plasma method, it was equal to $2.6 \mathrm{~g}\left[\mathrm{H}_{2}\right] / \mathrm{kWh}$ with a $\mathrm{CH}_{4}$ conversion ratio of $85.8 \%$ as shown in Fig. 9. In general, therefore, it seems that the hydrogen energetic mass yield from the RF plasma method tended to increase with an increase of the gas production rate. However, it was followed by a decrease of the $\mathrm{CH}_{4}$ conversion ratio.

This indicates that a slow rate of $\mathrm{CH}_{4}$ release from methane hydrate can optimize plasma decomposition of $\mathrm{CH}_{4}$ to produce hydrogen when using the RF plasma method. On the other hand, in methane hydrate decomposition by the MW plasma method, the hydrogen energetic mass yield tended to increase with the rise of the gas production rate, which was also followed by an increase of the $\mathrm{CH}_{4}$ conversion ratio. This leads to an optimization of plasma decomposition to produce hydrogen when there is a faster rate of $\mathrm{CH}_{4}$ release from methane hydrate. Consequently, this result indicates that there is a significant difference between these two plasma decomposition methods.

Fig. 10 shows the comparison summary of the performance's results of these two methods of in-liquid plasma. 


\section{Conclusions}

Plasma decomposition of methane hydrate by applying $2.45 \mathrm{GHz}$ Microwave irradiation and 27.12 MHz Radio Frequency irradiation was conducted under atmospheric pressure. The mechanism of reaction for the plasma decomposition of methane hydrate initiated with the methane hydrate dissociation (MHD) process in which $\mathrm{CH}_{4}$ and water were produced. It then continued to the simultaneously occurring steam methane reforming (SMR) process and methane cracking reaction (MCR) during which the released $\mathrm{CH}_{4}$ decomposed into $\mathrm{H}_{2}$, $\mathrm{CO}$ and other byproducts.

Methane hydrate could be decomposed to produce hydrogen with a purity of $42.1 \%\left(\mathrm{CH}_{4}\right.$ conversion ratio of $\left.85.8 \%\right)$ by the $2.45 \mathrm{GHz}$ Microwave plasma method using a conventional microwave oven, whereas the $27.12 \mathrm{MHz}$ Radio Frequency plasma inliquid method can provide a purity of $63.1 \%\left(\mathrm{CH}_{4}\right.$ conversion ratio of $99.1 \%$ ). Decomposition of methane hydrate by the Microwave plasma method can optimize plasma decomposition of $\mathrm{CH}_{4}$ to produce hydrogen at a fast rate of $\mathrm{CH}_{4}$ release from methane hydrate. Conversely, the methane hydrate decomposition by Radio Frequency plasma method occurs at a slow rate of $\mathrm{CH}_{4}$ release from methane hydrate.

Furthermore, for forthcoming research, in order to simulate the actual conditions of high pressure and low temperature at the subsea site where methane hydrate is in its stable state, experimentation on the decomposition of methane hydrate at high pressure will be conducted using argon plasma jet.

\section{References}

[1] H.F. Abbas, W.M.A. Wan Daud, Hydrogen production by methane decomposition: a review, Int. J. Hydrogen Energy 35 (3) (Feb. 2010) 1160-1190.

[2] N. Bundaleska, D. Tsyganov, R. Saavedra, E. Tatarova, F.M. Dias, C.M. Ferreira, Hydrogen production from methanol reforming in microwave 'tornado'-type plasma, Int. J. Hydrogen Energy 38 (22) (Jul. 2013) 9145-9157.

[3] S. Nomura, H. Toyota, M. Tawara, H. Yamashita, K. Matsumoto, Fuel gas production by microwave plasma in liquid, Appl. Phys. Lett. 88 (23) (2006) 231502.

[4] J. Fan, L. Zhu, Performance analysis of a feasible technology for power and high-purity hydrogen production driven by methane fuel, Appl. Therm. Eng. 75 (Jan. 2015) 103-114.

[5] J.L. Silveira, V.J. Martinelli, L.F. Vane, J.C. Freire Junior, R.A. Zanzi Vigouroux, C.E. Tuna, W.D.Q. Lamas, R.F.S. Paulino, Incorporation of hydrogen production process in a sugar cane industry: steam reforming of ethanol, Appl. Therm. Eng. 71 (1) (Oct. 2014) 94-103.

[6] A.E.E. Putra, S. Nomura, S. Mukasa, H. Toyota, Hydrogen production by reforming clathrate hydrates using the in-liquid, in: 11th International Conference on Sustainable Energy Technologies (SET-2012), 2012.
[7] M. Ozturk, I. Dincer, Thermodynamic analysis of a solar-based multi-generation system with hydrogen production, Appl. Therm. Eng. 51 (1-2) (Mar. 2013) 1235-1244.

[8] M. Jasinski, M. Dors, H. Nowakowska, G.V. Nichipor, J. Mizeraczyk, Production of hydrogen via conversion of hydrocarbons using microwave plasma, J. Appl. Phys. 44 (November) (2010) 7.

[9] S. Nomura, H. Toyota, S. Mukasa, H. Yamashita, T. Maehara, A. Kawashima, Production of hydrogen in a conventional microwave oven, J. Appl. Phys. 106 (7) (2009) 073306.

[10] D.-L. Li, D.-Q. Liang, S.-S. Fan, X.-S. Li, L.-G. Tang, N.-S. Huang, In situ hydrate dissociation using microwave heating: preliminary study, Energy Convers. Manag. 49 (8) (Aug. 2008) 2207-2213.

[11] A.E.E. Putra, S. Nomura, S. Mukasa, H. Toyota, Hydrogen production by radio frequency plasma stimulation in methane hydrate at atmospheric pressure, Int. J. Hydrogen Energy 37 (21) (Nov. 2012) 16000-16005.

[12] E. Dendy Sloan, C. Koh, Clathrate Hydrates of Natural Gases, third ed. 20074156, CRC Press, 2007, p. 701.

[13] Ayhan Demirbas, Methane Gas Hydrate, Springer, 2010.

[14] A. Boyano, A.M. Blanco-Marigorta, T. Morosuk, G. Tsatsaronis, Exergoenvironmental analysis of a steam methane reforming process for hydrogen production, Energy 36 (4) (Apr. 2011) 2202-2214.

[15] N.-J. Kim, S.-S. Park, H.T. Kim, W. Chun, A comparative study on the enhanced formation of methane hydrate using CM-95 and CM-100 MWCNTs, Int. Commun. Heat. Mass Transf. 38 (1) (Jan. 2011) 31-36.

[16] L.A. Stern, S. Circone, S.H. Kirby, W.B. Durham, Anomalous Preservation of Pure Methane Hydrate at 1 atm, J. Phys. Chem. B. (2001) 1756-1762.

[17] V. Alexiades, Methane hydrate formation and decomposition, Electron. J. Differ. Equations 17 (2009) 1-11.

[18] S. Nomura, S. Mukasa, H. Toyota, H. Miyake, H. Yamashita, T. Maehara a Kawashima, F. Abe, Characteristics of in-liquid plasma in water under higher pressure than atmospheric pressure, Plasma Sources Sci. Technol. 20 (3) (Jun. 2011) 034012.

[19] S. Mukasa, T. Maehara, S. Nomura, H. Toyota, A. Kawashima, Y. Hattori Y. Hashimoto, H. Yamashita, Growth of bubbles containing plasma in water by high-frequency irradiation, Int. J. Heat. Mass Transf. 53 (15-16) (Jul. 2010) 3067-3074.

[20] S. Mukasa, S. Nomura, H. Toyota, T. Maehara, H. Yamashita, Internal conditions of a bubble containing radio-frequency plasma in water, Plasma Sources Sci. Technol. 20 (3) (Jun. 2011) 034020.

[21] Y.-F. Wang, Y.-S. You, C.-H. Tsai, L.-C. Wang, Production of hydrogen by plasma-reforming of methanol, Int. J. Hydrogen Energy 35 (18) (Sep. 2010) 9637-9640.

[22] S. Nomura, A.E.E. Putra, S. Mukasa, H. Toyota, H. Yamashita, Fuel gas production by plasma in a micorwave oven at atmospheric, in: Proceedings of the ASME/JSME 2011 8th Thermal Engineering Joint Conference, 2011, pp. 1-6.

[23] C. Giavarini, F. Maccioni, Self-preservation at low pressures of methane hydrates with various Gas contents, Ind. Eng. Chem. Res. 43 (20) (Sep. 2004) 6616-6621.

[24] S. Circone, S.H. Kirby, L. a Stern, Direct measurement of methane hydrate composition along the hydrate equilibrium boundary, J. Phys. Chem. B 109 (19) (May 2005) 9468-9475.

[25] G.K. Anderson, Enthalpy of dissociation and hydration number of methane hydrate from the Clapeyron equation, J. Chem. Thermodyn. 36 (12) (Dec. 2004) 1119-1127. 